\title{
Salt intakes and BMI in pre-adolescent children
}

\author{
Sarah G. Fleming, Joanna Bowtell and Gloria J. Davies \\ London South Bank University, London, UK
}

An increased exposure to dietary $\mathrm{Na}$ and salt intake in pre-adolescent children as well as being overweight may increase the propensity for raised blood pressure in later life ${ }^{(1,2)}$. The present study has examined the prevalence of high dietary salt intake $(\mathrm{Na}$ and $\mathrm{Cl})$ in a group of pre-adolescent schoolchildren.

Children aged 7-13 years from five schools within the Inner London area were recruited. The purpose and requirements of the study were explained to the children at school and those interested in taking part were given an information pack. Written informed consent from the children's guardians was sought before taking part in the study.

A total of 277 study information packs were distributed to children attending schools within the Inner London area. Subsequently, fiftyfive consent forms were returned (response rate of 20\%); however, of the fifty-five children that took part only nineteen (fourteen White British, one White Irish, two Black Caribbean, one Asian Pakistani and one White mixed Asian) were included in this study (response rate of $7 \%$ ) as a result of incomplete food diaries. Anthropometric measurements (height, body weight and waist circumference) were taken from each child. Subjects completed a $3 \mathrm{~d}$ weighed-food diary and habitual salt intake was estimated using dietary analysis software (CompEat ${ }^{\mathrm{TM}}$ version 5.8.0; Nutrition Systems, Grantham, Lincs., UK). Salt added during cooking or at the table was not taken into account. Mean nutrient intakes were compared with reference nutrient intakes (RNI) ${ }^{(3)}$ using one sample $t$ tests.

\begin{tabular}{|c|c|c|c|c|c|c|c|}
\hline & \multicolumn{3}{|c|}{ Boys $(n 12)$} & \multicolumn{3}{|c|}{ Girls $(n 7)$} & \multirow[b]{2}{*}{ RNI } \\
\hline & Mean & SD & Range & Mean & $\mathrm{SD}$ & Range & \\
\hline Age (years) & 8.6 & 1.7 & $7-13$ & 8.9 & 1.3 & $7-11$ & \\
\hline BMI $\left(\mathrm{kg} / \mathrm{m}^{2}\right)$ & 18.5 & 3.8 & $15.6-26.4$ & 18.8 & 2.7 & $16.1-24.1$ & \\
\hline Waist $(\mathrm{cm})$ & 62.5 & 11.9 & $51.0-87.0$ & 60.2 & 5.8 & $56.0-72.5$ & \\
\hline $\mathrm{Na}(\mathrm{mg} / \mathrm{d})$ & 2695 & 822 & $1853-4282$ & 1851 & 423 & $1121-2385$ & 1200 \\
\hline $\mathrm{Cl}(\mathrm{mg} / \mathrm{d})$ & 3604 & 1026 & $2159-5150$ & 2653 & 737 & $1516-3818$ & 1800 \\
\hline Salt (g/d) & 6.8 & 2.1 & $4.7-10.9$ & 4.7 & 1.1 & $2.9-6.1$ & $<5$ \\
\hline
\end{tabular}

For both the boys and the girls mean dietary $\mathrm{Na}$ and $\mathrm{Cl}$ intakes were significantly higher than the RNI for age and gender $(P<0.001)$. Consequently, mean habitual salt intake was significantly above the recommended guidelines of $<5 \mathrm{~g} / \mathrm{d}$ for the boys $(P<0.05)$, although the girls were within recommended guidelines. In addition, the boys had a significantly higher salt intake than the girls $(P<0.05)$. These overweight boys and girls (BMI $>91$ st centile) with excess intakes of dietary $\mathrm{Na}$ and $\mathrm{Cl}$, and salt, may be at increased risk of ill-health in later life.

1. Chinn S \& Rona RJ (2001) Br Med J 322, 24-26.

2. Scientific Advisory Committee on Nutrition (2003) Salt and Health. London: The Stationery Office.

3. Department of Health (1991) Dietary Reference Values for Food Energy and Nutrients for the UK. London: H. M. Stationery Office. 